Revisão

Review

\title{
Modulação genética da miostatina e do gene ACTN3 em hipertrofia e força muscular: uma revisão integrativa
}

\section{Genetic Modulation of Myostatin and Actn3 Gene in Muscular Hypertrophy and Force: an Integrative Review}

\author{
Márcia Cristiane Araújo ${ }^{1,2} \mathrm{PhD}$; Andréia de Sousa Costa ${ }^{2}$; Cristien Martins Frota ${ }^{2}$; Antonio Carlos Leal \\ Cortez $^{\S 2,3}$ MS; Antonio Carlos Gomes ${ }^{4}$ PhD; Herbert Gustavo Simões ${ }^{1} \mathrm{PhD}$
}

Recebido em: 03 de julho de 2017. Aceito em: 30 de outubro de 2017. Publicado online em: 29 de março de 2018.

\begin{abstract}
Resumo
Introdução: A análise dos diversos fatores genéticos, principalmente os relacionados aos polimorfismos de DNA, têm sido investigados na busca de uma melhor compreensão dos mecanismos relacionados à hipertrofia e força muscular. Dentre os diversos genes polimórficos relacionados ao tema estão a miostatina e o gene $\alpha$ actinina-3 (ACTN3).

Objetivo: Avaliar a modulação do gene da miostatina na hipertrofia muscular esquelética e do gene ACTN3 na regulação dos níveis de força.

Métodos: Estudo de revisão integrativa no qual foram pesquisados artigos que tivessem avaliado a modulação genética da hipertrofia muscular esquelética e da força. Fizeram parte desta investigação estudos originais e de revisão, publicados em português, inglês e espanhol, entre os anos de 1995 a 2017, selecionados nas bases de dados SciELO e Pubmed, utilizando-se três conjuntos de intersecção de termos de busca bibliográfica em português: a) "miostatina" e "hipertrofia muscular esquelética" e/ou "genética"; e b) "exercício físico" ou "treinamento aeróbico" ou "treinamento de força" ou "rendimento esportivo" e "ACTN3" e/ou "força muscular" e/ou genética. Em inglês: a) "myostatin"and "skeletal muscle hypertrophy" and/or genetics; and b) "physical exercise" and "aerobic training", strength training, sports performance) and "ACTN3" "muscular strength" and/or "genetic". E em espanhol: "miostatina" y "hipertrofia muscular esquelética" y/o genética; y b) "ejercicio físico" o
Pontos-Chave Destaque
- O genótipo RR577 do ACTN3
está associado com a força e
com o tamanho da área de
secção transversa do músculo
esquelético.
- Há correlação do alelo R com
fibras glicolíticas de contração
rápida e níveis médios de
testosterona significativamente
mais elevados.
- A miostatina atua na inibição da hipertrofia muscular esquelética, e também pode ser modulada geneticamente pelo exercício físico.

"entrenamiento aeróbico" o "entrenamiento de fuerza" o "rendimiento desportivo) y "ACTN3" o "fuerza muscular" y/o genética".

Resultados e Discussão: Os estudos apontaram: a) associação do genótipo RR577 do ACTN3 com a força e o tamanho da área de secção transversa do músculo esquelético; b) correlação do alelo R com fibras glicolíticas de contração rápida e níveis médios de testosterona significativamente mais elevados; e c) o polimorfismo do ACTN3 está relacionado ao treinamento de alta intensidade. As evidências apontaram que a miostatina atua na inibição da hipertrofia muscular esquelética, e também pode ser modulada geneticamente pelo exercício físico.
\end{abstract}

\footnotetext{
$\S$ Autor correspondente: Antonio Carlos Leal Cortez - e-mail: antoniocarloscortez@hotmail.com.

Afiliações: ${ }^{1}$ Programa de Pós-Graduação Stricto Sensu em Educação Física da Universidade Católica de Brasília - UCB; ${ }^{2}$ Centro Universitário Santo Agostinho - UNIFSA; ${ }^{3}$ Programa de Pós-graduação Stricto Sensu em Enfermagem e Biociências (PPgEnfBio) da Universidade Federal do Estado do Rio de Janeiro (UNIRIO); ${ }^{4}$ Academia Brasileira de Treinadores do Comitê Olímpico Brasileiro (COB), RJ.
} 
Conclusão: A literatura aponta evidências de que o polimorfismo do ACNT3 está relacionado com o treinamento de alta intensidade, ressaltando que, segundo os resultados dos estudos, houve correlação do alelo R, com fibras glicolíticas de contração rápida e com os níveis de testosterona significativamente mais elevados. Sendo assim, o gene ACTN3 está correlacionado com o desenvolvimento da força muscular e a folistatina, proteína antagônica da miostatina, está associada ao aumento da massa muscular.

Palavras-chave: hipertrofia, força muscular, miostatina, polimorfismo.

\begin{abstract}
Introduction: The analysis of several genetic factors, especially those related to DNA polymorphisms, has been investigated in the search for a better understanding of the mechanisms related to hypertrophy and muscle strength. Among the several polymorphic genes related to the subject are myostatin and ACTN3.

Objective: To evaluate the modulation of the myostatin gene in skeletal muscle hypertrophy and the ACTN3 gene in the regulation of strength levels.

Methods: An integrative review study in which articles were searched that assessed the genetic modulation of skeletal muscle hypertrophy and strength. Original and review studies, published in Portuguese, English and Spanish, between 1995 and 2017, selected in the SciELO and PubMed databases, were carried out using three sets of intersection of bibliographic search: In English: a) "myostatin" and "skeletal muscle hypertrophy" and/or genetics; and b) "physical exercise" and "aerobic training", strength training, sports performance) and "ACTN3" "muscular strength" and/or "genetic". In Portuguese: a) "miostatina" e "hipertrofia muscular esquelética" e/ou "genética"; e b) "exercício físico" ou "treinamento aeróbico" ou "treinamento de força" ou "rendimento esportivo" e "ACTN3" e/ou "força muscular" e/ou genética. And in Spanish: "miostatina" y "hipertrofia muscular esquelética" y/o genética; y b) "ejercicio físico" o "entrenamiento aeróbico" o "entrenamiento de fuerza" o "rendimiento desportivo) y "ACTN3" o "fuerza muscular" y/o genética".
\end{abstract}

Results and Discussion: Studies indicated: a) association of RR577 genotype of ACTN3 with the strength and size of the cross-sectional area of skeletal muscle; b) correlation of the R allele with fast contracting glycolytic fibers and significantly higher mean levels of testosterone; and, c) ACTN3 polymorphism is related to high intensity training. Evidence has pointed out that myostatin acts on inhibition of skeletal muscle hypertrophy, as well as being genetically modulated by physical exercise.

Conclusion: The literature showed evidence that the ACNT3 polymorphism is related to the high intensity training, emphasizing that according to the results of the studies, there was a correlation of the $\mathrm{R}$ allele with fast contracting glycolytic fibers and with testosterone levels higher. Thus, the ACTN3 gene is correlated with the development of muscle strength and follistatin, an antagonistic protein of myostatin, is associated with increased muscle mass. Keywords: hypertrophy, muscle strength, myostatin, polymorphism.

\title{
Modulação genética da miostatina e do gene ACTN3 em hipertrofia e força muscular: uma revisão Integrativa
}

\section{Introdução}

$\mathrm{Na}$ atualidade, é crescente o número de pessoas que procuram as academias de ginástica em busca de resultados no que se diz respeito ao aumento de massa muscular esquelética, ou seja, resultados 
hipertróficos(1). O treinamento físico pode promover a hipertrofia do músculo esquelético e aumentar a sua capacidade de gerar força(2). Todavia, os termos hipertrofia e força muitas vezes são utilizados como sinônimos quando, na verdade, tratam-se de termos fisiologicamente distintos(3). A hipertrofia muscular esquelética, refere-se ao aumento da área de secção transversa do músculo esquelético, a partir da biossíntese de novas estruturas envolvidas na contração muscular, sendo uma das principais adaptações geradas no músculo em decorrência do treinamento físico(4,5). De acordo com Fernandes et al.(6) o músculo esquelético responde a estímulos fisiológicos como o exercício físico, remodelando-se para se adaptar às novas demandas impostas por esse estímulo. Esta adaptação é feita por estímulos extracelulares, que chegam à membrana celular e interagem com receptores, ativando assim, vias de sinalização intracelular, as quais resultam em alterações na transcrição gênica e síntese proteica e consequentemente promovem o remodelamento da musculatura, ou seja, a hipertrofia muscular, que pode gerar novos níveis de força(2).

As evidências apontam que a hipertrofia muscular, parece estar associada às modulações do gene da miostatina(6), membro da superfamília das proteína morfogenética óssea (BPM), é considerada um fator de crescimento transformador- B (TGF-B), também conhecido como fator- 8 de crescimento e diferenciação (GDF-8)(7). A miostatina é um importante regulador negativo do desenvolvimento do músculo esquelético. Essa proteína possui um agente antagônico denominado folistatina, que é expressa em diferentes tecidos e atua como um antagonista de diferentes membros da família TGF-B (transforming growth factor beta: fator de crescimento transformador beta é uma citocina multifuncional da família do fator de crescimento transformador, que inclui quatro isoformas diferentes e muitas outras proteínas de sinalização produzidas por todas as linhagens de glóbulos brancos(6). Amthor et al.(8) sugeriram haver uma grande afinidade e interação da folistatina com o aumento da massa muscular.
Com relação à força, a literatura tem relacionado essa capacidade física ao gene $\alpha$ actinina-3, ou simplesmente ACTN3, que é uma proteína presente nas fibras musculares esqueléticas tipo II, responsáveis pela contração rápida e desenvolvimento da força muscular(9). No entanto, faz-se importante a realização dessa revisão sistemática, uma vez que são poucos os trabalhos que explicam, de forma conjunta, os mecanismos que modulam a ação genética da proteína miostatina no desenvolvimento da hipertrofia muscular e da proteína do ACTN-3 no desenvolvimento da força muscular.

O presente estudo teve como objetivo avaliar a modulação do gene da miostatina na hipertrofia muscular esquelética e do gene ACTN3 na regulação dos níveis de força.

\section{Métodos}

\section{Desenho de estudo e seleção de artigos}

Estudo de revisão do tipo integrativa, cujos critérios de elegibilidade foram: estudos originais, do tipo ensaio clínico (aleatorizados ou não, controlados ou não) que fossem correlacionados a hipertrofia e força muscular. Os critérios de inclusão foram: 1) Que contivessem os termos de busca: em português: a) "miostatina" e "hipertrofia muscular esquelética" e/ou "genética"; e b) "exercício físico" ou "treinamento aeróbico" ou "treinamento de força" ou "rendimento esportivo" e "ACTN3" e/ou "força muscular" e/ou genética. Em inglês: a) "myostatin" and "skeletal muscle hypertrophy" and/or genetics; and b) "physical exercise" and "aerobic training", strength training, sports performance) and "ACTN3" "muscular strength" and/or "genetic". E em espanhol: "miostatina" y "hipertrofia muscular esquelética" y/o genética; y b) "ejercicio fisico" o "entrenamiento aeróbico" o "entrenamiento de fuerza" o "rendimiento desportivo) y "ACTN3" o "fuerza muscular" y/o genética" e 2) Que tivessem sido publicados entre os anos 1995 a 2017. Os critérios de exclusão foram: 1) Estudos de revisão; e 2) Estudos que relatassem sobre trabalho de hipertrofia e/ou de força e que examinassem outros genes que não foram objeto desta pesquisa. 
Primeiramente procedeu-se a uma triagem dos artigos com a leitura do título e resumo (quando disponíveis), e uma etapa de confirmação, pela leitura completa dos artigos. Os estudos de revisão foram utilizados para o desenvolvimento das análises dos resultados e discussão.

\section{Resultados e Discussão}

Depois de executada a estratégia de busca, foram encontrados 61 artigos, dos quais, foram extraídas informações necessárias, de acordo com o objetivo desta revisão. Quarenta e um destes foram excluídos por serem estudos de revisão. Portanto, fizeram parte desta revisão 20 artigos de estudos originais.

O número de indivíduos, em cada estudo realizado com seres humanos, variou de 10 a 1456 pessoas, com idade entre 7 e 40 anos, com predominância do gênero masculino. Dentre os estudos selecionados, desenho mais utilizado foi o observacional $(83,3 \%)$. A Tabela 1 apresenta os estudos resultados segundo a produção do gene ACTN3 relacionados ao exercício, sendo todos experimentais, com seres humanos. Os estudos examinaram amostras compostas por atletas de elite e indivíduos não treinados, objetivando analisar a relação entre exercício físico e a modulação do gene ACTN3, na hipertrofia e força muscular. Os métodos mais frequentemente utilizados foram: genotipagem (amostras de sangue, saliva e biópsia muscular); testes de explosão; e testes de 1 repetição máxima (1RM). Observa-se associação do genótipo ACTN3 com força, e com tamanho da área de secção transversa do músculo(10), com aumento na quantidade de novas unidades motoras contráteis, em decorrência da hipertrofia muscular.

As evidências, apontaram que indivíduos com genótipos RR ou RX, portadores do alelo $\mathrm{R}$ produzem ACTN3, que possui ação específica na produção fibras glicolíticas de contração rápida (Tipo II). Portanto, estes indivíduos apresentam maior volume muscular e de força, ao contrário dos portadores do alelo $\mathrm{X}$ (homozigotos XX) que, devido à ausência da isoforma 3 não produzem $\operatorname{ACTN} 3(11)$, mas produzem ACTN2, que está presente no polimorfismo ACTN3(11-13). Assim, pode-se inferir o tipo de fibra, através da diferenciação quanto aos tipos de genótipos, em função de ausência ou presença de ACTN3. Em resumo, indivíduos homozigotos $\mathrm{XX}$, parecem não apresentar características de força de contração rápida em sua composição genética, ao contrário de indivíduos portadores do alelo $\mathrm{R}$, presente em fibras do tipo II(13).

Ahmetov et al.(14) concluíram que o nível hormonal de testosterona, em um indivíduo, pode ser explicado pelo genótipo ACTN3. Os autores ressaltaram, ainda, que as médias dos níveis de testosterona são significativamente mais elevadas em indivíduos portadores do alelo R e do polimorfismo ACTN3, sendo que o efeito anabólico desse hormônio pode sobrepor os ganhos de força e potência muscular, resultando na presença de ACTN3 na estrutura muscular.

Segundo Gentil et al.(15) o polimorfismo ACTN3, não tem influência no aumento dos níveis de força muscular, em resposta ao treinamento físico realizado em curto prazo e com baixa intensidade. No entanto, Hogarth et al.(16) sugeriram que a deficiência e/ou supressão do gene ACTN3 diminui a força e o desempenho muscular. Face à controvérsia, esses resultados, devem ser confirmados por outros estudos experimentais que utilizem protocolos de treinamento com maior volume e/ ou intensidade em estágios de duração mais longos.

Em síntese, os estudos relacionados a produção do gene ACTN3 e exercício físico apontaram: a) Associação do genótipo RR577 do ACTN3 com a força e o tamanho da área de secção transversa do músculo esquelético; $b$ ) Correlação do alelo R com fibras glicolíticas de contração rápida e níveis médios de testosterona significativamente mais elevados; e, c) A gênese (aumento) do polimorfismo do ACTN3 está relacionada ao treinamento de alta intensidade.

Para a análise da miostatina foram incluídos 08 artigos originais, com pesquisas experimentais, objetivando analisar a relação entre exercício físico e a modulação do gene miostatina em casos específicos (Tabela 2). Dos 08 estudos, cinco foram realizados em modelo animal (ratos); dois em modelo humano homens e um com modelo duplo (homens e ratos). Os métodos mais utilizados foram: genotipagem (amostras de sangue, 
Tabela 1 - Caracterização dos estudos selecionados de acordo com o autor, ano de publicação, banco de dados, amostra, objetivo, procedimentos metodológicos e resultados segundo a produção do gene ACTN3 e exercício físico

\begin{tabular}{|c|c|c|c|c|}
\hline Autor & Amostra & Objetivo & Desenho de estudo e Métodos & Resultados \\
\hline Clarkson et al. (10) & $\begin{array}{l}\mathrm{N}=355 \text { mulheres } \\
\mathrm{N}=247 \text { homens }\end{array}$ & $\begin{array}{l}\text { Identificar polimorfismos de } \\
\text { nucleotídeo único } \\
\text { nonsynonymous com efeitos } \\
\text { funcionais sobre a massa e } \\
\text { força muscular em seres } \\
\text { humanos. }\end{array}$ & $\begin{array}{l}\text { Experimental. Doze semanas de } \\
\text { treinamento de exercício de } \\
\text { resistência progressiva } \\
\text { (Contração voluntária Máxima e } \\
\text { 1RM). Banco e medidor de } \\
\text { tensão/ Ressonância magnética/ } \\
\text { Avaliação antropométrica/ } \\
\text { Genotipagem (amostra de } \\
\text { sangue). }\end{array}$ & $\begin{array}{l}\text { Existência de } \\
\text { associações genéticas do } \\
\text { genótipo ACTN3 com } \\
\text { força e tamanho } \\
\text { muscular. }\end{array}$ \\
\hline Vicente et al.(13) & $\mathrm{N}=90$ homens & $\begin{array}{l}\text { Quantificar a associação } \\
\text { entre a distribuição de tipo de } \\
\text { fibra muscular e } \\
\text { polimorfismo. }\end{array}$ & $\begin{array}{l}\text { Observacional. RT-PCR / } \\
\text { Medidas Antropométricas / } \\
\text { Dinamômetro/ Tradutor de torque } \\
\text { calibrado (aplicado em esforços } \\
\text { submáximos) / Biópsia do vasto } \\
\text { lateral direito/ Amostras de } \\
\text { sangue. }\end{array}$ & $\begin{array}{l}\text { Os resultados mostram } \\
\text { um efeito aditivo de cada } \\
\text { alelo R para aumentar a } \\
\text { potência em homens, } \\
\text { bem como um possível } \\
\text { papel do gene ACTN3 } \\
\text { em associado tipo de } \\
\text { fibra IIb e a ausência na } \\
\text { Fibra tipo I. }\end{array}$ \\
\hline Norman et al.(12) & $\begin{array}{l}\mathrm{N}=61 \text { homens } \\
\mathrm{N}=89 \text { mulheres }\end{array}$ & $\begin{array}{l}\text { Avaliar o impacto do gene } \\
\text { ACTN3 sobre a força } \\
\text { muscular. }\end{array}$ & $\begin{array}{l}\text { Observacional. Teste de Wingate } \\
\text { (em cicloergômetro) / teste de } \\
\text { fadiga dinâmica e concêntrica } \\
\text { máxima/ extensão de joelhos em } \\
\text { diferentes velocidades angulares. } \\
\text { Avaliação de dobras cutâneas / } \\
\text { Genotipagem (Biópsia do vasto } \\
\text { lateral e amostras de sangue) }\end{array}$ & $\begin{array}{l}\text { Genótipos RR } \\
\text { apresentam maior massa } \\
\text { corporal. }\end{array}$ \\
\hline
\end{tabular}

Nonsynonymous (mutação de nucleotídeo que altera a sequência de aminoácidos de uma proteína); ACTN3 (proteína de ligação cruzada de F-actina); $R T P C R$ (é uma reação da transcriptase reversa, seguida de reação em cadeia da polimerase); genótipos $R R, R X e X X$ (expressões funcionais das formas da proteína $\alpha$-actinina-3); Genotipagem (é o processo pelo qual identificamos pequenas regiões do DNA denominadas marcadores, que variam de indivíduo para indivíduo); $A C T N 3 R 577 X$ (expressão da proteína $\alpha$-actina-3 que contribui para a construção do componente contrátil em fibras de contração rápida que compõem o poder do músculo esquelético); alelo $\mathbf{R}$ (responsável pela produção de $\alpha$ - actinina 3); homozigotos $\mathbf{X X}$ ( alelos genéticos idênticos, com genótipo mutante $X X$ deriva da proteína não funcional, porém essa deficiência não resulta em patologia nem compromete a função muscular); gene 577XX (preditor do fenótipo de $\alpha$-actinina-3 deficiente); gene 577RR (produz normalmente $\alpha$-actinina-3 


\begin{tabular}{|c|c|c|c|c|}
\hline Autor & Amostra & Objetivo & Desenho de estudo e Métodos & Resultados \\
\hline Ruiz et al.(23) & $\begin{array}{l}\mathrm{N}=243 \text { homens e } 91 \\
\text { mulheres (grupo } \\
\text { controle) } \\
\mathrm{N}=31 \text { homens e } 35 \\
\text { mulheres (atletas) }\end{array}$ & $\begin{array}{l}\text { Examinar a associação do } \\
\text { polimorfismo ACTN3 } \\
\text { R577X com a potência } \\
\text { muscular "explosiva". }\end{array}$ & $\begin{array}{l}\text { Observacional. Avaliação do } \\
\text { agachamento e saltar contra- } \\
\text { movimento / Teste usando uma } \\
\text { plataforma de sincronismo. } \\
\text { Extração ADN genômico / } \\
\text { Genotipagem (amostra de sangue) }\end{array}$ & $\begin{array}{l}\text { Não encontraram uma } \\
\text { associação entre o } \\
\text { polimorfismo ACTN3 } \\
\text { R577X e o voleibol. }\end{array}$ \\
\hline Gentil et al.(15) & $\mathrm{N}=141$ homens & $\begin{array}{l}\text { Investigar a associação do } \\
\text { polimorfismo R577X com as } \\
\text { respostas ao treinamento de } \\
\text { resistência em homens } \\
\text { jovens. }\end{array}$ & $\begin{array}{l}\text { Experimental. } 11 \text { semanas de } \\
\text { treinamento / } 1 \text { RM supino e } \\
\text { extensão de joelho / pico de } \\
\text { torque concêntrico / Treinamento } \\
\text { de resistência = } 2 \text { séries de } 8-12 \\
\text { repetições de cinco exercícios. } \\
\text { Genotipagem foi realizada } \\
\text { utilizando a enzima de restrição } \\
\text { Ddel. }\end{array}$ & $\begin{array}{l}\text { O polimorfismo ACTN3 } \\
\text { não influência no } \\
\text { aumento dos níveis de } \\
\text { força muscular em } \\
\text { resposta ao treinamento } \\
\text { físico realizado em curto } \\
\text { prazo e de baixa } \\
\text { resistência. }\end{array}$ \\
\hline Montenegro et al.(24) & $\begin{array}{l}\mathrm{N}=111 \text { meninos } \\
(7-12 \text { anos de } \\
\text { idade })\end{array}$ & $\begin{array}{l}\text { Comparar o desempenho } \\
\text { anaeróbico conforme as } \\
\text { configurações genéticas RR, } \\
\text { RX e XX da proteína } \\
\text { ACTN3 em crianças. }\end{array}$ & $\begin{array}{l}\text { Observacional. Teste de corrida } \\
\text { de } 40 \text { metros para a medida da } \\
\text { potência muscular e o índice de } \\
\text { fadiga/ Amostra da saliva (serviu } \\
\text { para a extração do DNA e } \\
\text { identificação do polimorfismo do } \\
\text { ACTN3). }\end{array}$ & $\begin{array}{l}\text { Não reportou diferenças } \\
\text { significativas da potência } \\
\text { anaeróbica e de índice de } \\
\text { fadiga entre os grupos de } \\
\text { crianças com } \\
\text { configuração genética } \\
\text { RR, RX e XX do } \\
\text { ACTN3. }\end{array}$ \\
\hline Norman et al.(25) & $\begin{array}{l}\mathrm{N}=143 \text { atletas de } \\
\text { ambos os sexos }\end{array}$ & $\begin{array}{l}\text { Investigar a composição } \\
\text { muscular e modulação do } \\
\text { desempenho humano pelo } \\
\text { genótipo ACTN3. }\end{array}$ & $\begin{array}{l}\text { Observacional. Sprint de } 30 \mathrm{~s} / \\
\text { ciclismo, corrida, ginástica/ } \\
\text { exercícios de } \\
\text { resistência/Genotipagem (Biópsia } \\
\text { do vasto lateral) / Análise de } \\
\text { glicose }\end{array}$ & $\begin{array}{l}\text { O genótipo ACTN3 } \\
\text { modula a resposta ao } \\
\text { exercício. }\end{array}$ \\
\hline
\end{tabular}




\begin{tabular}{|c|c|c|c|c|}
\hline Autor & Amostra & Objetivo & Desenho de estudo e Métodos & Resultados \\
\hline Erskine et al.(11) & $\mathrm{N}=51$ homens & $\begin{array}{l}\text { Investigar as associações } \\
\text { entre polimorfismos da } \\
\text { angiotensina- enzima de } \\
\text { conversão (ACE), a-actinina- } \\
3 \text { (ACTN3), e músculo } \\
\text { esquelético, fenótipos e as } \\
\text { respostas ao treinamento } \\
\text { resistido (TR) }\end{array}$ & $\begin{array}{l}\text { Observacional. Força isométrica } \\
\text { máxima de tendão patelar/ } \\
\text { volume muscular do quadríceps } \\
\text { femoral/ Extensão unilateral de } \\
\text { joelho/ } 1 \mathrm{RM} / \text { Genotipagem } \\
\text { (Amostras de sangue e saliva) }\end{array}$ & $\begin{array}{l}\text { Portadores do alelo } \mathrm{R} \\
\text { ACTN3 tinha maior } \\
\text { volume muscular, 1RM e } \\
\mathrm{VO}_{2} \text { máx que } \\
\text { homozigotos } \mathrm{XX} \text {. }\end{array}$ \\
\hline Ahmetov et al.(14) & $\begin{array}{l}\mathrm{N}=119 \text { Homens } \\
\mathrm{N}=90 \text { Mulheres }\end{array}$ & $\begin{array}{l}\text { investigar a associação do } \\
\text { gene ACTN3 polimorfismo } \\
\text { R577X com os níveis de } \\
\text { testosterona em atletas. }\end{array}$ & $\begin{array}{l}\text { Observacional. Homens = Esqui } \\
\text { alpino, Beisebol, esqui, } \\
\text { canoagem, voleibol. } \\
\text { Mulheres = Esqui alpino, } \\
\text { Patinagem artística, patinação } \\
\text { velocidade e voleibol. Kit de } \\
\text { Proba-GS/ Genotipagem / } \\
\text { Discriminação alélica / soro dos } \\
\text { atletas (análise da testosterona) }\end{array}$ & $\begin{array}{l}\text { Os níveis médios de } \\
\text { testosterona são mais } \\
\text { elevados em indivíduos } \\
\text { portadores do alelo R } \\
\text { ACTN3 do que em } \\
\text { homozigotos XX. }\end{array}$ \\
\hline Eynon et al.(34) & $\begin{array}{l}\mathrm{N}=1456: \text { ( } 888 \text { atletas } \\
\text { e } 568 \text { grupo } \\
\text { controle) }\end{array}$ & $\begin{array}{l}\text { Determinar a associação de } \\
\text { ACTN3 com atletas de elite e } \\
\text { equipes de esporte em três } \\
\text { coortes de atletas europeus } \\
\text { de equipe de desporto. }\end{array}$ & $\begin{array}{l}\text { Observacional. Genotipagem } \\
\text { (amostra de saliva e de sangue } \\
\text { periférico) }\end{array}$ & $\begin{array}{l}\text { Atletas de força são mais } \\
\text { propensos a ter o } \\
\text { genótipo } 577 \mathrm{RR}(\mathrm{em} \\
\text { oposição ao } 577 \mathrm{XX}) \text {. }\end{array}$ \\
\hline João et al. (35) & $\begin{array}{l}\mathrm{N}=73 \text { ginastas } \\
(\mathrm{N}=37 \text { Homens } \\
\mathrm{N}=36 \text { Mulheres })\end{array}$ & $\begin{array}{l}\text { Analisar a frequência do } \\
\text { genótipo e do alelo de uma } \\
\text { actinina } 3 \text { (ACTN3) e } \\
\text { enzima conversora da } \\
\text { angiotensina (ACE) em um } \\
\text { grupo de ginastas. }\end{array}$ & $\begin{array}{l}\text { Observacional. Amostra de saliva } \\
\text { (Recolhida utilizando um } \\
\text { cotonete de algodão estéril) }\end{array}$ & $\begin{array}{l}\text { Encontrou-se a } \\
\text { prevalência ACTN3 RX } \\
\text { e maior frequência de } \\
\text { ocorrência alelo R. }\end{array}$ \\
\hline Zaken et al. (36) & $\begin{array}{l}\mathrm{N}=137 \text { corredores } \\
\mathrm{N}=91 \text { nadadores } \\
\mathrm{N}=217 \text { controles } \\
\text { Todos os } \\
\text { participantes do sexo } \\
\text { masculino. }\end{array}$ & $\begin{array}{l}\text { Comparar Genótipos e alelos } \\
\text { polimorfismo ACTN3 } \\
\text { R577X entre os corredores e } \\
\text { nadadores especializados em } \\
\text { diferentes distâncias. }\end{array}$ & $\begin{array}{l}\text { Observacional. Corredores (dois } \\
\text { grupos= um de longa distância } \\
\text { outro de curta distância) e } \\
\text { nadadores (dois grupos= um de } \\
\text { longa distância outro de curta } \\
\text { distância). } \\
\text { Genotipagem (amostras de } \\
\text { sangue) }\end{array}$ & $\begin{array}{l}\text { Nos corredores de curta } \\
\text { distância encontrou-se } \\
\text { menor frequência do } \\
\text { genótipo XX e maior } \\
\text { frequência do genótipo } \\
\text { RR. }\end{array}$ \\
\hline
\end{tabular}


Tabela 2 - Caracterização dos estudos relacionados segundo amostra, objetivo, procedimentos metodológicos e resultados segundo a produção do gene miostatina e exercício físico.

\begin{tabular}{|c|c|c|c|c|}
\hline Autor & Amostra & Objetivo & $\begin{array}{c}\text { Desenho de estudo e } \\
\text { Métodos }\end{array}$ & Resultados \\
\hline Hittel et al.(26) & $\begin{array}{l}\mathrm{N}=10 \text { homens } \\
\mathrm{N}=16 \text { ratos } \\
\text { Modelo } \\
\text { combinado. }\end{array}$ & $\begin{array}{l}\text { Investigar a relação de } \\
\text { miostatina e resistência à } \\
\text { insulina. }\end{array}$ & $\begin{array}{l}\text { Treinamento aeróbico leve } \\
\text { a moderado em homens e } \\
\text { exercício aeróbico em } \\
\text { ratos. } \\
\text { IVGTT (Teste para } \\
\text { determinar a sensibilidade } \\
\text { da insulina / Amostra de } \\
\text { sangue / Biópsia muscular. }\end{array}$ & $\begin{array}{l}\text { Os autores identificaram que } \\
\text { os níveis de miostatina } \\
\text { muscular podem ser regulados } \\
\text { pelo treinamento aeróbico. }\end{array}$ \\
\hline $\begin{array}{l}\text { Matsakas et } \\
\text { al.(27) }\end{array}$ & $\begin{array}{l}\mathrm{N}=10 \text { ratos } \\
\text { Modelo animal. }\end{array}$ & $\begin{array}{l}\text { Analisar o efeito de dois } \\
\text { sistemas de exercícios } \\
\text { baseados em resistência seja } \\
\text { um treinamento de mergulho } \\
\text { forçado de alto impacto ou } \\
\text { roda voluntária de intensidade } \\
\text { moderada que corre sobre as } \\
\text { propriedades adaptativas do } \\
\text { músculo tibial anterior e } \\
\text { plantar de ratos MSTN. }\end{array}$ & $\begin{array}{l}\text { Divisão de três grupos: } 1 \text { - } \\
\text { de natação; } 2 \text { - em uma } \\
\text { roda de corrida e } 3 \text { - grupo } \\
\text { controle. Coleta de sangue } \\
\text { / dissecação dos animais / } \\
\text { Imunohistoquímica e } \\
\text { histologia. }\end{array}$ & $\begin{array}{l}\text { O treinamento resistido } \\
\text { modula a miostatina. }\end{array}$ \\
\hline $\begin{array}{l}\text { Laurentino et } \\
\text { al.(28) }\end{array}$ & $\mathrm{N}=29$ homens & $\begin{array}{l}\text { Determinar se as respostas } \\
\text { semelhantes de força e } \\
\text { hipertrofia muscular } \\
\text { observados após exercício de } \\
\text { resistência tanto de baixa } \\
\text { quanto de alta intensidade } \\
\text { estão associadas a mudanças } \\
\text { semelhantes em mRNA } \\
\text { mensageiro de expressão de } \\
\text { genes selecionados envolvidos } \\
\text { da miostatina. }\end{array}$ & $\begin{array}{l}\text { Três grupos: Baixa } \\
\text { intensidade } \mathrm{N}=10 \text { / Baixa } \\
\text { intensidade associada com } \\
\text { restrição moderada do } \\
\text { fluxo sanguíneo } \mathrm{N}=10 \mathrm{e} \\
\text { alta intensidade } \mathrm{N}=9 \text { / } \\
\text { Força máxima dinâmica (1 } \\
\mathrm{RM} \text { ) extensão do joelho. }\end{array}$ & $\begin{array}{l}\text { Os exercícios de baixąontinua } \\
\text { intensidade associados com } \\
\text { moderada restrição do fluxo } \\
\text { sanguíneo foi capaz de induzir } \\
\text { ganhos em 1RM semelhantes } \\
\text { aos observados após } \\
\text { exercícios de alta intensidade. } \\
\text { Estas respostas podem ser } \\
\text { relacionadas com a redução } \\
\text { concomitante na miostatina e } \\
\text { aumento em isoformas } \\
\text { folistatina, expressão do gene } \\
\text { mRNA. }\end{array}$ \\
\hline
\end{tabular}




\begin{tabular}{|c|c|c|c|c|}
\hline Autor & Amostra & Objetivo & $\begin{array}{c}\text { Desenho de estudo e } \\
\text { Métodos }\end{array}$ & Resultados \\
\hline Ko et al.(29) & $\begin{array}{l}\mathrm{N}=20 \text { (ratos de } 5 \\
\text { meses) } \\
\mathrm{N}=20 \text { (ratos de } \\
24 \text { meses) } \\
\text { Modelo animal. }\end{array}$ & $\begin{array}{l}\text { Investigar o possível efeito } \\
\text { anti- envelhecimento do } \\
\text { exercício aeróbico sobre } \\
\text { músculo esquelético. }\end{array}$ & $\begin{array}{l}\text { Teste de carga de peso (os } \\
\text { ratos sendo forçados a } \\
\text { correr na esteira } \\
\text { motorizada durante } 30 \\
\text { min) / Hematoxilina / } \\
\text { eosina / Polimerase de } \\
\text { transição de ARNm de } \\
\text { miostatina / Western blot } \\
\text { de miostatina / } \\
\text { Imunohistoquímica de 5- } \\
\text { bromo-2-desoxiuridina } \\
\text { reversa. }\end{array}$ & $\begin{array}{l}\text { Exercício em esteira melhora } \\
\text { a massa muscula e força } \\
\text { através da supressão de } \\
\text { mRNA miostatina. }\end{array}$ \\
\hline Paoli et al.(19) & $\mathrm{N}=18$ homens & $\begin{array}{l}\text { Investigar a influência de dois } \\
\text { meses de Treinamento } \\
\text { resistido e as dietas com } \\
\text { diferentes teores de proteína } \\
\text { no plasma da miostatina. }\end{array}$ & $\begin{array}{l}\text { Participantes ativos (que } \\
\text { praticavam de } 5 \text { a } 6 \text { horas } \\
\text { semanais de desportos de } \\
\text { equipe). Amostra de } \\
\text { sangue / Dinamômetro } \\
\text { para preensão / dobras } \\
\text { cutâneas/ Perimetria / } \\
\text { balança eletrônica / } \\
\text { Ressonância magnética / } \\
\text { Avaliação nutricional }\end{array}$ & $\begin{array}{l}\text { Os níveis plasmáticos de } \\
\text { miostatina e IGF-1 } \\
\text { correlacionados aumentaram } \\
\text { significativamente no grupo } \\
\text { HP (de alta proteína). }\end{array}$ \\
\hline Latres et al.(21) & $\begin{array}{l}\mathrm{N}=324 \\
\text { camundongos } \\
\text { Modelo animal. }\end{array}$ & $\begin{array}{l}\text { Relacionar a inativação da } \\
\text { miostatina com o tratamento } \\
\text { de doenças de emaciação } \\
\text { muscular. }\end{array}$ & $\begin{array}{l}\text { Exercício em esteira. } \\
\text { Ressonância plasmática. }\end{array}$ & $\begin{array}{l}\text { Com o uso do anticorpo } \\
\text { REGN1033 humano gerado } \\
\text { para agir como antagonista da } \\
\text { miostatina, foi possível } \\
\text { concluir que a massa muscular } \\
\text { e função em ratos jovens e } \\
\text { idosos foram reforçados, e } \\
\text { teve efeitos benéficos em } \\
\text { modelos de atrofia muscular } \\
\text { esquelética. }\end{array}$ \\
\hline
\end{tabular}




\begin{tabular}{|c|c|c|c|c|}
\hline Autor & Amostra & Objetivo & $\begin{array}{c}\text { Desenho de estudo } \\
\text { e Métodos }\end{array}$ & Resultados \\
\hline $\begin{array}{l}\text { Bassi et } \\
\text { al.(20) }\end{array}$ & $\begin{array}{l}\mathrm{N}=24 \text { ratos } \\
\text { Modelo } \\
\text { animal. }\end{array}$ & $\begin{array}{l}\text { Analisar o efeito do } \\
\text { exercício sobre o } \\
\text { padrão de miostatina } \\
\text { muscular e expressão } \\
\text { da proteína em duas } \\
\text { desordens metabólicas } \\
\text { importantes, isto é, } \\
\text { obesidade e diabetes. }\end{array}$ & $\begin{array}{l}\text { Aferição de } \\
\text { Glicemia } \\
\text { (Glicocímetro } \\
\text { portátil). } \\
\text { Animais e comida } \\
\text { pesados diariamente } \\
\text { / amostra de sangue / } \\
\text { natação em barris de } \\
\text { plástico / dissecação } \\
\text { do músculo } \\
\text { gastrocnêmio. }\end{array}$ & $\begin{array}{l}\text { Os resultados } \\
\text { demonstraram que o } \\
\text { exercício pode modular } \\
\text { a expressão aumentada } \\
\text { de miostatina no } \\
\text { músculo de ratos } \\
\text { diabéticos e sugere que } \\
\text { a miostatina pode } \\
\text { participar na } \\
\text { homeostase energética. } \\
\text { Foi observado o } \\
\text { aumento de massa } \\
\text { muscular pela inibição } \\
\text { da miostatina. }\end{array}$ \\
\hline $\begin{array}{l}\text { Minderis et } \\
\text { al.(30) }\end{array}$ & $\begin{array}{l}\mathrm{N}=32 \\
\text { camundongos } \\
\text { Modelo } \\
\text { animal. }\end{array}$ & $\begin{array}{l}\text { Investigar se a } \\
\text { disfunção da miostatina } \\
\text { promoveria o ganho de } \\
\text { massa muscular e de } \\
\text { pico de força isométrica } \\
\text { do músculo sóleo em } \\
\text { resposta a sobrecarga } \\
\text { funcional. }\end{array}$ & $\begin{array}{l}\text { Sobrecarga } \\
\text { funcional do } \\
\text { músculo sóleo. }\end{array}$ & $\begin{array}{l}\text { Disfunção da } \\
\text { miostatina. }\end{array}$ \\
\hline
\end{tabular}

imunohistoquímica e dissecação dos animais) e exercícios de corrida e natação. Os estudos mostraram que a expressão da miostatina é regulada em situações nas quais são evidenciadas alterações na massa muscular(17-21). O papel de inibidor do crescimento muscular exercido pela miostatina, foi comprovado somente no final da década de 90(7), mais especificadamente, em 1997, quando foi demonstrado que mutações no gene que codifica esta proteína, foram capazes de promover um ganho extraordinário de massa muscular em bovinos, o que posteriormente, também, foi observado em cães da raça Whippet(22). É robusto o corpo de evidências que apontam que tanto exercícios aeróbicos quanto exercício resistidos parecem melhorar a massa muscular e a força, através da supressão de mRNA miostatina, pois, o exercício pode modular a expressão aumentada de miostatina no músculo e da isoforma da folistatina, esta última, proteína capaz de modular a hipertrofia do músculo esquelético, através da inibição do GDF-8 (Miostatina) (20,23,28,29).

Algumas patologias que promovem intenso catabolismo, como câncer e AIDS, estão positivamente relacionadas ao aumento na expressão de miostatina. Entretanto, o treinamento de força exerce uma modulação genética sobre a expressão e/ou atividade da miostatina, promovendo a hipertrofia do músculo esquelético. Sendo assim podemos destacar que a miostatina, pode influenciar a atividade da folistatina, modulando a hipertrofia, evitando a perda de massa muscular nesses grupos(27,31).

A associação encontrada, em alguns estudos, do ACTN3 com a miostatina, destaca a interdependência da força com o aumento da área de secção transversa do músculo, ou seja, o aumento na quantidade de fibras contráteis está associado à quantidade de força gerada pelo indivíduo. Outro achado importante foi que há determinação do tipo de fibra muscular relacionada ao tipo de genótipo, em função da ausência ou presença do ACTN3.

\section{Pontos fortes e limitações do estudo}

Um ponto forte do estudo foi que o tema genética relacionada ao exercício e os benefícios para a saúde ainda se trata de tema relativamente novo, sendo que foi possível serem identificadas controvérsias na literatura. Dessa forma, ficou ressaltada a contribuição do presente estudo para o conhecimento. 
Uma limitação do estudo foi que a realização de uma metanálise poderia identificar a doseresposta de exercícios em relação ao ACTN3 e à miostatina, todavia, observou-se que são escassos os estudos experimentais que tenham examinado esses genes em relação a força e hipertrofia. Além disso, dentre os poucos estudos identificados, são ainda mais raros os realizados em modelo humano, principalmente os relacionados à miostatina, cuja maioria foi realizada em modelo animal.

\section{Conclusão}

Alguns estudos demonstraram associação do ACTN3 com a miostatina, destacando a interdependência da força com o aumento da área de secção transversa do músculo, ou seja, o aumento na quantidade de fibras contráteis está associado à quantidade de força gerada pelo indivíduo. Assim, observou-se que a determinação do tipo de fibra muscular, devido a diferenciação quanto ao tipo de genótipo em função da ausência ou presença do ACTN3. Nesse sentido, identificou-se que o genótipo RR577 do ACTN3 está associado com a força e com o tamanho da área de secção transversa do músculo esquelético.

A literatura também exibiu evidências de que o polimorfismo do ACTN3 se relaciona ao treinamento resistido de alta intensidade. Entretanto, parece haver controvérsia quanto à influência do polimorfismo ACTN3 no aumento dos níveis de força muscular, em resposta ao treinamento físico realizado em curto prazo e com baixa intensidade. Assim, outros estudos experimentais que utilizem protocolos de treinamento com maior volume e/ ou intensidade em estágios de duração mais longos devem ser conduzidos para esclarecer estas questões.

Além disso, entre os estudos que participaram desta revisão, houve consistência na correlação do alelo $\mathrm{R}$ com as fibras glicolíticas de contração rápida e com os níveis de testosterona significativamente mais elevados.

Quanto à miostatina, esta proteína parece ter o papel de inibidor no crescimento muscular e tanto exercícios aeróbios quanto exercícios resistidos parecem melhorar a massa muscula e a força através da supressão de mRNA miostatina e da expressão aumentada de folistatina, proteína antagônica da miostatina.

Pode-se concluir, que o gene ACTN3 está correlacionado com o desenvolvimento da força muscular e a folistatina, proteína antagônica da miostatina, está associada ao aumento da massa muscular. No entanto, sugere-se que outros estudos sejam realizados para que a temática seja melhor esclarecida.

\section{Declaração de conflito de interesses}

$\mathrm{O}$ estudo não possui nenhum conflito de interesses.

\section{Declaração de financiamento}

Financiamento próprio.

\section{Referências}

1. Ravagnani FC de P, Júnior ATDC, Werk $\mathrm{R}$ de, Coelho $\mathrm{C}$ de F. Composição corporal e objetivos na procura de atividades físicas supervisionadas entre iniciantes em programa de exercícios físicos em academia de Botucatu-SP. Fitness \& Performance Journal. 2007;6(3): 147151.

2. American College of Sports Medicine. American College of Sports Medicine position stand. Progression models in resistance training for healthy adults. Medicine and Science in Sports and Exercise. [Online] 2009;41(3): 687-708. Available

from: doi:10.1249/MSS.0b013e3181915670

3. Arruda DP de, Assumpção C de O, Urtado CB, Dorta LN de O, Rosa MRR, Zabaglia $\mathrm{R}$, et al. Relação entre treinamento de força e redução do peso corporal. RBPFEX Revista Brasileira de Prescrição e Fisiologia do Exercício. [Online] 2012;4(24). Available from: http://www.rbpfex.com.br/index.php/rbpf ex/article/view/291 [Accessed: 7th March 2018]

4. Glass DJ. Skeletal muscle hypertrophy and atrophy signaling pathways. The International Journal of Biochemistry \& Cell Biology. [Online] 2005;37(10): 19741984. Available from: doi:10.1016/j.biocel.2005.04.018 
5. Goldspink G. Gene expression in muscle in response to exercise. Journal of Muscle Research and Cell Motility. 2003;24(2-3): 121-126.

6. Fernandes T, Soci UPR, Alves CR, Carmo EC do, Barros JG, Oliveira EM de. Determinantes moleculares da hipertrofia do músculo esquelético mediados pelo treinamento físico: estudo de vias de sinalização. Revista Mackenzie de Educação Física e Esporte. [Online] 2009;7(1). Available from: http://editorarevistas.mackenzie.br/index. $\mathrm{php} /$ remef/article/view/1238 [Accessed: 7th March 2018]

7. McPherron AC, Lee SJ. Double muscling in cattle due to mutations in the myostatin gene. Proceedings of the National Academy of Sciences of the United States of America. 1997;94(23): 12457-12461.

8. Amthor H, Connolly D, Patel K, BrandSaberi B, Wilkinson DG, Cooke J, et al. The expression and regulation of follistatin and a follistatin-like gene during avian somite compartmentalization and myogenesis. Developmental Biology. [Online] 1996;178(2): 343-362. Available from: doi:10.1006/dbio.1996.0223

9. Pasqua LA, Artioli GG, Pires O, De F, Bertuzzi R. ACTN3 gene and sports performance: a candidate gene to success in short and long duration events. Revista Brasileira de Cineantropometria \&amp; Desempenho Humano. [Online] 2011;13(6): 477-483. Available from: doi:10.5007/1980-0037.2011v13n6p477

10. Clarkson PM, Devaney JM, GordishDressman H, Thompson PD, Hubal MJ, Urso $M$, et al. ACTN3 genotype is associated with increases in muscle strength in response to resistance training in women. Journal of Applied Physiology (Bethesda, Md.: 1985). [Online] 2005;99(1): 154-163. Available from: doi:10.1152/japplphysiol.01139.2004

11. Erskine RM, Williams AG, Jones DA, Stewart CE, Degens H. The individual and combined influence of ACE and ACTN3 genotypes on muscle phenotypes before and after strength training. Scandinavian Journal of Medicine \& Science in Sports. [Online] 2014;24(4): 642-648. Available from: doi:10.1111/sms. 12055

12. Norman B, Esbjörnsson M, Rundqvist H, Osterlund $\mathrm{T}$, von Walden $\mathrm{F}$, Tesch PA. Strength, power, fiber types, and mRNA expression in trained men and women with different ACTN3 R577X genotypes. Journal of Applied Physiology (Bethesda, Md.: 1985). [Online] 2009;106(3): 959965. Available from: doi:10.1152/japplphysiol.91435.2008

13. Vincent B, De Bock K, Ramaekers M, Van den Eede E, Van Leemputte M, Hespel P, et al. ACTN3 (R577X) genotype is associated with fiber type distribution. Physiological Genomics. [Online] 2007;32(1): 58-63. Available from: doi:10.1152/physiolgenomics.00173.2007

14. Ahmetov II, Donnikov AE, Trofimov DY. Actn3 genotype is associated with testosterone levels of athletes. Biology of Sport. [Online] 2014;31(2): 105-108. Available from: doi:10.5604/20831862.1096046

15. Gentil P, Pereira RW, Leite TKM, Bottaro M. ACTN3 R577X Polymorphism and Neuromuscular Response to Resistance Training. Journal of Sports Science \& Medicine. 2011;10(2): 393-399.

16. Hogarth MW, Houweling PJ, Thomas KC, Gordish-Dressman H, Bello L, Cooperative International Neuromuscular Research Group (CINRG), et al. Evidence for ACTN3 as a genetic modifier of Duchenne muscular dystrophy. Nature Communications. [Online] 2017;8: 14143. Available from: doi:10.1038/ncomms14143

17. Lee S-J. Regulation of muscle mass by myostatin. Annual Review of Cell and Developmental Biology. [Online] 2004;20: 61-86. Available from: 
doi:10.1146/annurev.cellbio.20.012103.1 35836

18. Patel K, Amthor $\mathrm{H}$. The function of Myostatin and strategies of Myostatin blockade-new hope for therapies aimed at promoting growth of skeletal muscle. Neuromuscular disorders: NMD. [Online] 2005;15(2): 117-126. Available from: doi:10.1016/j.nmd.2004.10.018

19. Paoli A, Pacelli QF, Neri M, Toniolo L, Cancellara P, Canato M, et al. Protein supplementation increases postexercise plasma myostatin concentration after 8 weeks of resistance training in young physically active subjects. Journal of Medicinal Food. [Online] 2015;18(1): 137-143. Available from: doi:10.1089/jmf.2014.0004

20. Bassi D, Bueno $\mathrm{P}$ de $\mathrm{G}$, Nonaka KO, Selistre-Araujo HS, Leal AM de O. Exercise alters myostatin protein expression in sedentary and exercised streptozotocin-diabetic rats. Archives of Endocrinology and Metabolism. [Online] 2015;59(2): 148-153. Available from: doi:10.1590/2359-3997000000028

21. Latres E, Pangilinan J, Miloscio L, Bauerlein R, Na E, Potocky TB, et al. Myostatin blockade with a fully human monoclonal antibody induces muscle hypertrophy and reverses muscle atrophy in young and aged mice. Skeletal Muscle. [Online] 2015;5: 34. Available from: doi:10.1186/s13395-015-0060-8

22. Mosher DS, Quignon P, Bustamante CD, Sutter NB, Mellersh CS, Parker HG, et al. A mutation in the myostatin gene increases muscle mass and enhances racing performance in heterozygote dogs. PLoS genetics. [Online] 2007;3(5): e79. Available doi:10.1371/journal.pgen.0030079

23. Ruiz JR, Fernández del Valle M, Verde Z, Díez-Vega I, Santiago C, Yvert T, et al. ACTN3 R577X polymorphism does not influence explosive leg muscle power in elite volleyball players. Scandinavian
Journal of Medicine \& Science in Sports. [Online] 2011;21(6): e34-41. Available from: doi:10.1111/j.16000838.2010.01134.x

24. Montenegro RC, Paz CR, Montenegro Neto AN, Araújo Filho VS, Fernandes PR, Fernandes Filho J. Desempenho anaeróbico e ACTN3 em crianças. Motricidade. [Online] 2013;9(4): 47-53. Available from: doi:10.6063/motricidade.9(4).1135

25. Norman B, Esbjörnsson M, Rundqvist H, Österlund T, Glenmark B, Jansson E. ACTN3 genotype and modulation of skeletal muscle response to exercise in human subjects. Journal of Applied Physiology (Bethesda, Md.: 1985). [Online] 2014;116(9): 1197-1203. Available from: doi:10.1152/japplphysiol.00557.2013

26. Hittel DS, Axelson M, Sarna N, Shearer J, Huffman KM, Kraus WE. Myostatin decreases with aerobic exercise and associates with insulin resistance. Medicine and Science in Sports and Exercise. [Online] 2010;42(11): 20232029. Available from: doi:10.1249/MSS.0b013e3181e0b9a8

27. Matsakas A, Mouisel E, Amthor H, Patel K. Myostatin knockout mice increase oxidative muscle phenotype as an adaptive response to exercise. Journal of Muscle Research and Cell Motility. [Online] 2010;31(2): 111-125. Available from: doi:10.1007/s10974-010-9214-9

28. Laurentino GC, Ugrinowitsch C, Roschel H, Aoki MS, Soares AG, Neves M, et al. Strength training with blood flow restriction diminishes myostatin gene expression. Medicine and Science in Sports and Exercise. [Online] 2012;44(3): 406-412. Available from: doi:10.1249/MSS.0b013e318233b4bc

29. Ko IG, Jeong JW, Kim YH, Jee YS, Kim $\mathrm{SE}, \mathrm{Kim} \mathrm{SH}$, et al. Aerobic exercise affects myostatin expression in aged rat skeletal muscles: a possibility of antiaging effects 
of aerobic exercise related with pelvic floor muscle and urethral rhabdosphincter. International Neurourology Journal. [Online] 2014;18(2): 77-85. Available from: doi:10.5213/inj.2014.18.2.77

30. Minderis P, Kilikevicius A, Baltusnikas J, Alhindi Y, Venckunas T, Bunger L, et al. Myostatin dysfunction is associated with reduction in overload induced hypertrophy of soleus muscle in mice. Scandinavian Journal of Medicine \& Science in Sports. [Online] 2016;26(8): 894-901. Available from: doi:10.1111/sms. 12532

31. Zimmers TA, Davies MV, Koniaris LG, Haynes P, Esquela AF, Tomkinson KN, et al. Induction of cachexia in mice by systemically administered myostatin. Science (New York, N.Y.). [Online] 2002;296(5572): 1486-1488. Available from: doi:10.1126/science.1069525 